\title{
Students' Experience with Collaborative Engineering Design Challenges in a Middle School Engineering Course (Evaluation)
}

\section{Dr. Jessica D. Gale, Georgia Institute of Technology}

Dr. Jessica Gale is a Senior Research Scientist at Georgia Tech's Center for Education Integrating Science, Mathematics, and Computing (CEISMC). Her research focuses on project-based learning, STEM integration at the elementary and middle grades levels, design-based implementation research, and fidelity of implementation. Dr. Gale has a particular interest in project-based engineering in elementary school communities and the socio-cultural dimensions of pre-college engineering education. She received her M.A. and Ph.D. in Educational Studies from Emory University.

\section{Dr. Meltem Alemdar, Georgia Institute of Technology}

Dr. Meltem Alemdar is Associate Director and Senior Research Scientist at Georgia Tech's Center for Education Integrating Science, Mathematics, and Computing (CEISMC). Dr. Alemdar has experience evaluating programs that fall under the umbrella of educational evaluation, including K-12 educational curricula, K-12 STEM programs after-school programs, and comprehensive school reform initiatives. Across these evaluations, she has used a variety of evaluation methods, ranging from a multi-level evaluation plan designed to assess program impact to methods such as program monitoring designed to facilitate program improvement. She received her Ph.D. in Research, Measurement and Statistics from the Department of Education Policy at Georgia State University (GSU).

\section{Dr. Roxanne Moore, Georgia Institute of Technology}

Roxanne Moore is currently a Senior Research Engineer at Georgia Tech with appointments in the school of Mechanical Engineering and the Center for Education Integrating Mathematics, Science, and Computing (CEISMC). She is involved with engineering education innovations and research from K-12 up to the collegiate level. She received her Ph.D. in Mechanical Engineering from Georgia Tech in 2012. 


\section{Students' Experience with Collaborative Engineering Design Challenges in a Middle School Engineering Course (Evaluation)}

\section{Introduction}

The recent emergence of engineering as a curricular priority in K-12 schools has spurred the development and implementation of new approaches for engaging students of all ages in the engineering design process [1]. With this increased prominence of engineering as a $\mathrm{K}-12$ discipline, education researchers have begun to explore the outcomes of engineering education in the context of K-12 schools. One review of P-12 engineering students from $2000-2015$ documented an increase in engineering education research during this period, highlighting a number of themes within the literature including: student perceptions, attitudes, motivations, belief, and knowledge; teacher professional development, and outcomes of engineering curricular interventions [2]. At the same time, researchers have begun to describe the potential benefits of engaging K-12 students in the engineering design process. Cunningham and Kelley [3] propose a constellation of sixteen epistemic practices of engineering including: developing processes to solve problems, using systems thinking, applying mathematics and science to problem-solving, constructing models and prototypes, persisting and learning from failure, making evidence-based decisions, and working effectively in teams.

Another strand of emerging research explores how K-12 students engage in the engineering design process. For example, Wendell, Wright, and Paugh [4] describe the reflective decisionmaking practices observed in $2^{\text {nd }}$ through $5^{\text {th }}$ grade classrooms as students completed design activities within the Engineering is Elementary curricula. Previous research on the middle school curriculum described in this paper [5] utilizes longitudinal interview data to document progressions in how individual students describe their work with the stages of the engineering design process over the course of several exposures to the curriculum.

Researchers have also investigated how integrated STEM curricula promote the transfer of knowledge from one STEM subject or context to another, ultimately enhancing student learning [6], [7], [8]. Because STEM integration supports the specific and explicit connection of topics from different disciplines, it may make the retrieval of knowledge more efficient when applying that knowledge in a new setting [6]. A meta-analysis by Becker and Park [7] suggest that integrated STEM education has positive impacts on students' ability to transfer knowledge to new settings and problems. Consistent with this extant research, results of our recent study showed that the integrated engineering curriculum described in this paper significantly increased students' mathematics and science test scores [8]. In addition to investigating the transfer of specific knowledge within and across STEM disciplines, there is a long tradition of educational research concerned more generally with the extent to which the positive effects of a particular learning activity or intervention extend beyond the initial learning context [9].[10]. The current study does not formally assess knowledge transfer per se; however, by exploring how students approach a novel engineering task, the study begins to explore whether and how students apply what they learn about the engineering design process in the course to problemsolving in other contexts. 
Engineering education researchers have also taken a keen interest in the ways in which engineering may foster students' capacity for collaboration [11], [12]. Indeed, studies of successful practices among professional engineers clearly underscore the importance of teamwork and communication as central to the engineering design process [13]. Cunningham and Lachapelle describe cultivating collaboration as an important design principle for the development of inclusive K-12 engineering curricula, stating that "collaboration and teamwork afford students rich opportunities to develop expertise and identity as valued science and engineering contributors" [12]. Researchers examining collaboration among K-12 students engaged in engineering have identified patterns that emerge as students work together on engineering challenges. For example, Jordan and McDaniel [14] investigated how peer interactions influenced how $5^{\text {th }}$ grade students manage uncertainty as they complete a collaborative problem-solving task in which they were asked to design, build, and program robots to achieve specific objectives. Discourse analysis revealed peer responses characterized as either socially supportive or socially unsupported and demonstrated that students typically relied on supportive social responses to resolve the uncertainties they encountered as they engaged in the task. This paper focuses on exploring student perceptions of collaborative engineering design experience and the ways in which they collaborate as they complete a novel engineering design task.

The hope of curricular interventions is that, through engineering experiences, students will develop habits of mind than will enable them to apply the Engineering Design Process (EDP) to solve engineering problems [2]. However, as much of the research on students use of the EDP takes place contemporaneously with curricular interventions, there is much still to be learned about the lasting impressions experiences with engineering may make on students. Specifically, research on curricular interventions typically has not investigated whether after engaging in integrated STEM curricula in which students explicitly engage in the EDP, students are inclined to utilize the EDP when designing a solution to a novel engineering problem.

\section{Research Questions}

This study addresses the following research questions:

- How do students describe their experience participating in collaborative engineering design activities within their engineering course?

- How do students approach a novel engineering design task following their participation in the engineering course?

\section{Framework}

Models of EDP vary in terms of specific terminology and the sequence of activities; however, these models generally depict an iterative process for developing design solutions. For this research, the EDP shown in Figure 1 was used as the conceptual framework guiding the development and implementation of the curriculum. The curriculum requires utilizing the EDP within a problem-based learning context, while also emphasizing science and mathematics practices defined by the Next Generation Science Standards [15] and the Standards of 
Mathematical Practice [16], respectively. This EDP model was utilized by teachers as they guided students through the curriculum and served as the basis for the engineering design log (described below). From a qualitative analysis perspective, the EDP informed the development of protocols and coding schemes utilized to analyze student interview data.

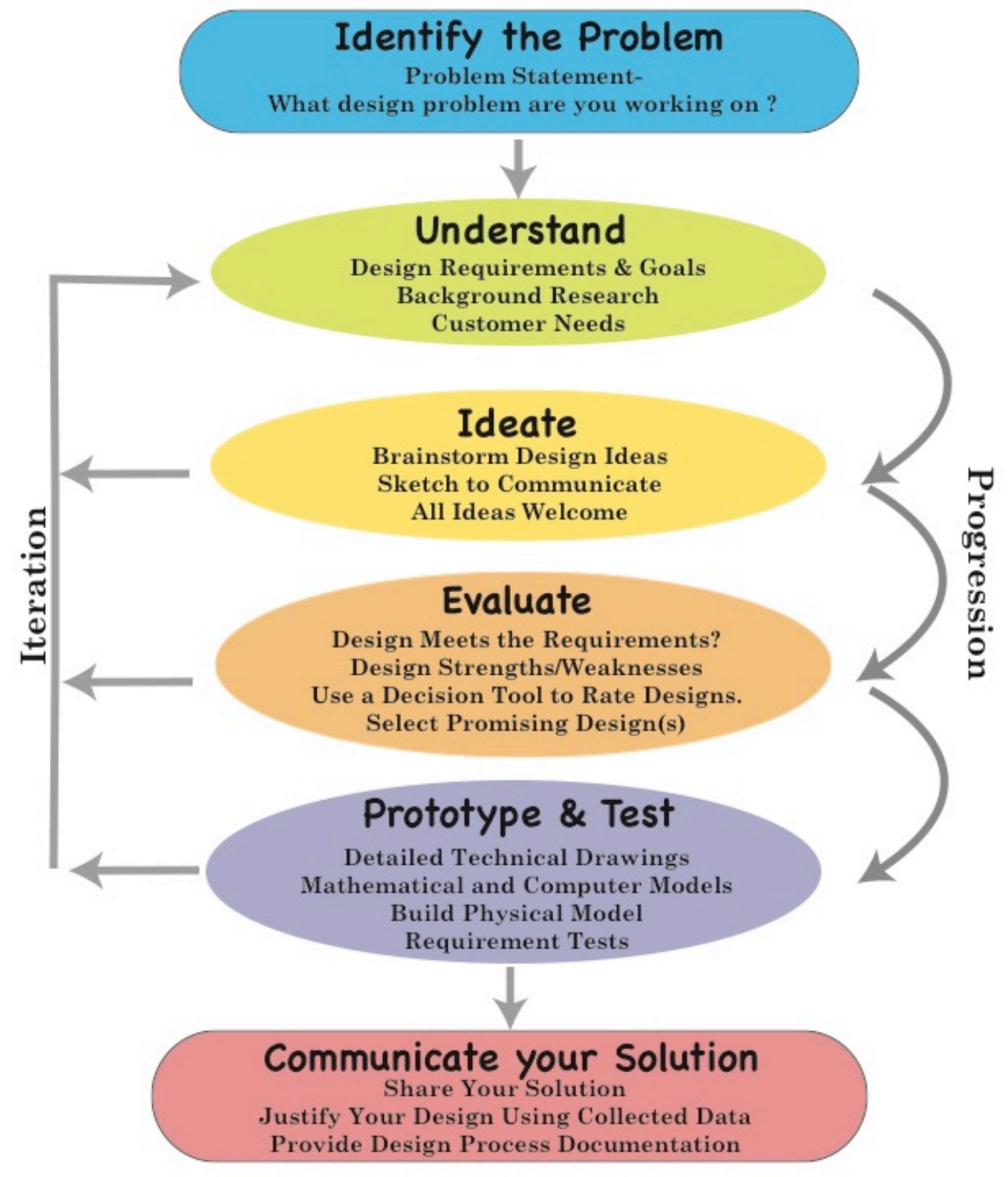

Figure 1. Engineering Design Process 


\section{Methods}

\section{Curriculum Context: The STEM-ID Courses}

As part of a National Science Foundation Math Science Partnership (MSP) middle school (6th8th grade) students participated in a semester-long STEM Innovation and Design (STEM-ID) course featuring a sequence of engineering design challenges intended to develop understanding of the engineering design process while reinforcing mathematics and science content. Each STEM-ID course included a series of design challenges in which students were asked to develop a solution to a specific engineering problem. For example, the sixth grade course includes multiple challenges centered around a carnival theme. Students first explore data and customer discovery by surveying students in their class and pitching an idea for a carnival food truck based on anticipated revenue and expense analysis. They then design a carnival game based on a pneumatic catapult, an activity which involves probability, profit, loss, break-even, and other mathematical concepts, as well as design of experiments, a scientific process. The course culminates in a design challenge where students change the trajectory of the pneumatic catapult by designing a new end effector to meet the requirements set forth in the design brief. Similarly, in eighth grade, students begin with a design challenge where they must design and prototype a cell phone holder for a partner in the class, meeting both the requirements set forth in the design brief and the requirements of their client. They then participate in a robotics challenge in which they apply physical science concepts and use 3D modeling software to design, prototype, and test "feet" for a walking insect-bot.

This study was conducted within the context of NSF MSP project's larger research agenda examining the implementation and outcomes of the engineering course in four middle schools within the partnering school district. The district is located in the urban fringe area outside a major city in the Southeastern United States. The district's student population is predominantly low-income, with approximately $67 \%$ of the students qualify for free/reduced lunch. The district is also relatively diverse, with student sub-groups including White (45\%), Black (44\%), Hispanic (7\%), and Other (5\%).

\section{Participants}

The study utilizes data collected from six groups of students $(n=21)$ enrolled in the engineering course during the Spring 2018 semester. We sampled three groups of students from each of two participating middle schools, including student groups from two eighth grade and one seventh grade at each school. At each school, students were randomly assigned to the STEM-ID course. In order to learn about the effects of multiple exposures to the engineering course, to the extent possible, we included students who took the course previously in either in $6^{\text {th }}$ or $7^{\text {th }}$ grade. Additionally, in order to increase the potential for productive discussion and engagement with the collaborative design task, whenever possible, the groups were comprised of students with previous experience working together in the course. As presented in Table 1 below, the composition of the groups varied somewhat with regard to grade level, gender, and students' previous course experience. As the data were gathered at the end of the course, after all students had participated in at least one full semester of the engineering curriculum, with the 
majority of students $(n=15)$ having been enrolled in the course multiple times. Nine students had participated in the course for two years and six eighth grade students had participated in the course all three years of middle school.

Table 1

Study Participants

\begin{tabular}{|c|c|c|c|c|c|c|c|}
\hline \multirow[t]{2}{*}{ School } & \multirow[t]{2}{*}{ Group } & \multirow[t]{2}{*}{$\begin{array}{l}\text { Grade } \\
\text { Level }\end{array}$} & \multicolumn{2}{|c|}{ Gender } & \multicolumn{3}{|c|}{$\begin{array}{l}\text { Engineering Course Experience } \\
\text { Number of students enrolled } \\
\text { for } 1,2, \text { or } 3 \text { years }\end{array}$} \\
\hline & & & $\bar{F}$ & $\mathrm{M}$ & 1 Year & 2 Years & 3 years \\
\hline \multirow[t]{3}{*}{ School 1} & $1(n=3)$ & 8 & 2 & 1 & 2 & 1 & 0 \\
\hline & $2(\mathrm{n}=2)$ & 7 & 2 & 0 & 0 & 2 & 0 \\
\hline & $3(n=4)$ & 8 & 2 & 2 & 2 & 1 & 1 \\
\hline \multirow[t]{3}{*}{ School 2} & $4(n=4)$ & 8 & 2 & 2 & 0 & 1 & 3 \\
\hline & $5(n=4)$ & 7 & 3 & 1 & 2 & 2 & 0 \\
\hline & $6(n=4)$ & 8 & 2 & 2 & 0 & 2 & 2 \\
\hline
\end{tabular}

\section{Data Sources}

Focus group discussions lasted approximately 30 minutes and were facilitated using a semistructured protocol, which asked students to reflect on various aspects of their experiences in the course including their experience working in collaborative groups. Focus groups were audio-recorded and transcribed for analysis.

Following the focus group discussions, the same student groups participated in a novel engineering performance task that was not part of the curriculum (the "elephant task"). In this task, students were given a problem scenario in which a traveling circus needed a design solution to move an elephant from ground level into an elevated train car. The scenario provided students with certain constraints (e.g. size and dimensions of the train car). They were also given everyday materials (e.g. shoebox, string, ruler, card stock), and 20 minutes to design a solution to the challenge. During the design session, the facilitating researcher primarily observed as students worked on the challenge. The researcher did offer clarification by reviewing the task description if students asked questions or seemed confused about the task. In order to elicit student commentary on their design process, the facilitating researcher occasionally asked students to describe what they were doing ("tell me about what you are doing now"?). Following the design session, students participated in a short debriefing conversation in which they were asked to share their design solutions and reflect on how their group collaborated during the task. The task description, which was read to students and provided as a handout for reference, is presented in Figure 2. below. 
You are hired by a traveling circus to help improve the process of moving the circus performers, equipment, and animals between locations. Often, the circus uses trains to transport everything safely between cities. The circus is looking for inexpensive, quick ways to load their elephants onto the train. In addition, any devices used to load the elephants on the train must also be easy to store and transport. Assume that the train cars are 6 feet off the ground. Remember, the elephants must be well-taken care of and cannot be injured in any way.

Details about the dimensions of the train car (a boxcar with sliding doors) and elephants are below:
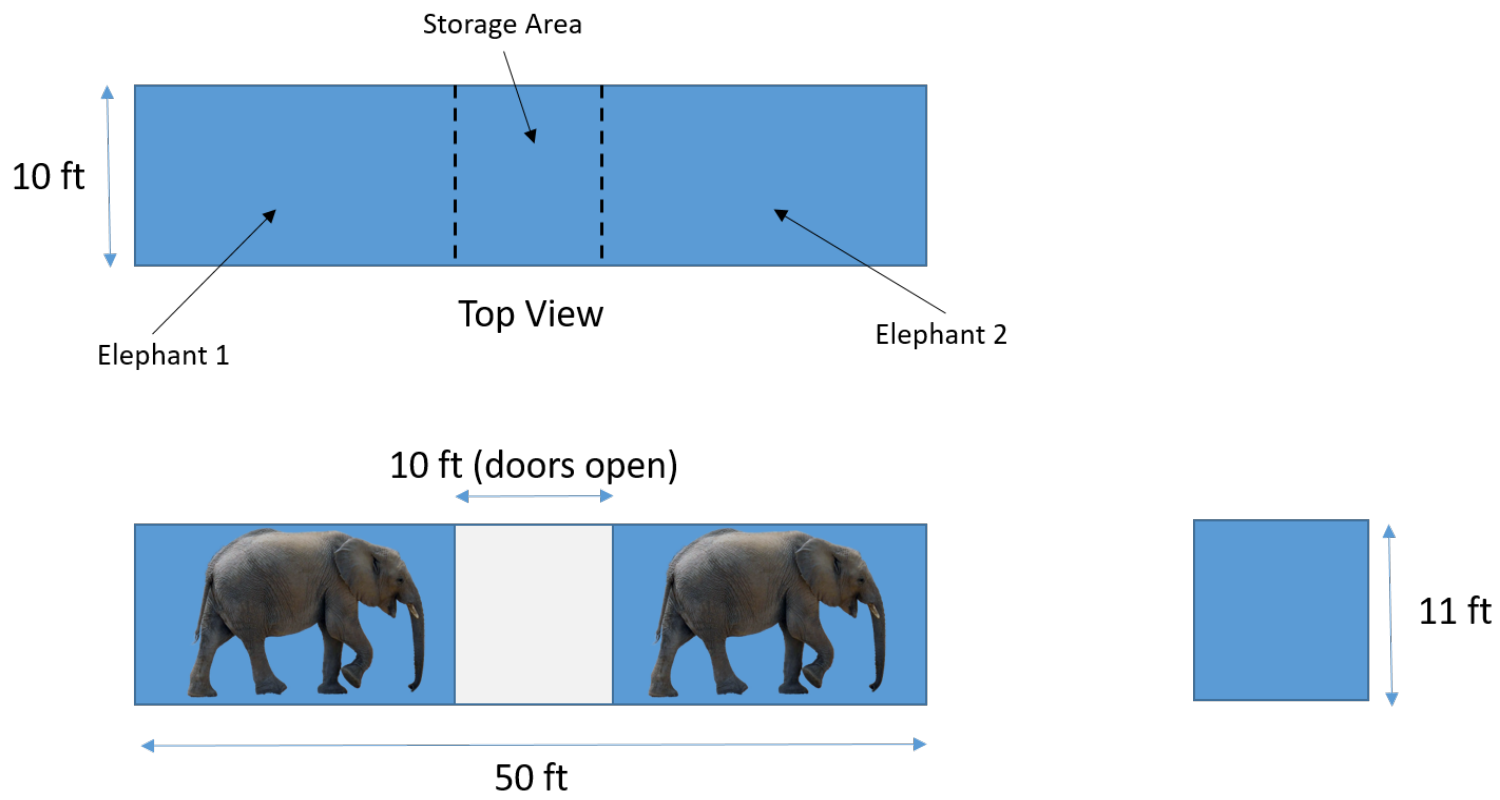

Front View

Side View

The elephants are approximately 10 feet tall and weigh 10,000 pounds (or 5 tons.) Elephants are good at walking, but cannot climb anything steeper than a slope of $1 \mathrm{ft}$ of rise for every 2 $\mathrm{ft}$ of run. Also, elephants do not eat peanuts-that is a myth.

Figure 2. The Elephant Task

Two researchers were present during both the focus group discussion and the performance task, with one researcher acting as a facilitator and the other taking detailed notes using a structured field note guide. This field note guide included space to record observations of student actions during the design task as well as observations related to engagement with the engineering 
design process (depicted in Figure 1) and collaboration. Specifically, the field note guide included checkboxes for the researcher to indicate which, if any, of the stages of the engineering design process students engaged in and whether they demonstrated any of the following behaviors related to collaboration: proposing ideas to the group, encouraging others to share ideas, providing input on others ideas, incorporating multiple group members' ideas into final design, group decision-making strategies (e.g. voting), dismissing/rejecting individual ideas.

\section{Data Analysis}

Field note guides, transcripts and audio-recordings of each session were analyzed to identify the various approaches student groups utilized to address the task, and the degree to which these approaches resembled the design process students used previously in their engineering course. Specifically, field note guides and transcripts were coded using the NVIVO software program to identify instances related to collaboration and student engagement with each of the stages of the engineering design process. The definitions of the stages of the engineering design process used for this coding are included in Table 2. Because field notes, transcripts, and audio-recordings did not always clearly identify which or how many of the students engaged in particular actions as they completed the task, we coded for EDP engagement at the group level and referred to field notes to note any apparent differences in engagement within each group.

\section{Findings}

Findings pertaining to each research question are presented below. First, we summarize focus group findings related to student perspectives on their experiences with collaborative engineering design within the course. Next, we present findings from the administration of the novel engineering design task, focusing on three areas: the general ways in which students approached the task, the extent to which students utilized the engineering design process as they completed the task, and student collaboration within the context of the task.

\section{Research Question 1: How do students describe their experience participating in collaborative engineering design activities within their engineering course?}

Consistent with previous research on the curriculum [5] students reported that they enjoyed participating in the engineering design challenges within the course, noting ways in which the challenges fostered understanding of the engineering design process, collaboration, and the application of mathematics and science concepts. Students reported clear differences in the degree to which they engaged in collaboration in their engineering course, with students at School 1 confirming that engineering challenges were generally completed in groups and students at School 2 reporting that their teacher most often implemented design challenges with the whole class, often performing demonstrations or having individual students volunteer for specific tasks while the rest of the class observed.

In discussing the value of collaboration, students at School 1, where collaboration was commonplace, tended to emphasize the ways in which working with their classmates allowed them to complete the design challenges more efficiently or effectively. For example, one student in Group 1 discussed how she was able to complete more trials when testing a prototype 
with a group than she could if she were working individually, noting "it was better when you test it with somebody else." Similarly, students in group 2 described the division of labor within their group, noting that each person in the group had an assigned role as they were testing their prototypes, noting that in groups "we get our work done faster". Likewise, students in Group 3 emphasized group roles and communication during group work, stating "each of us basically gets assigned a task to do, and we just communicate with each other." Group 3 also discussed their experience working with their classmates to evaluate competing designs, stating "if it's a design thing, we would have multiple designs and try to see which one was best... which one had the most things, which worked properly." Although students at School 2 had limited experience working collaboratively on design challenges, students in one group discussed how they would have appreciated the opportunity for more group work, stating, "It'd be better to work in groups, 'cause some people understand, so they can help you, but we just do it individually."

Student reflections following their completion of the performance task provide additional insight into their perspectives on collaborative engineering design. Asked to discuss how their groups collaborated during the task, students tended to provide relatively positive reviews, even in cases where students faced clear challenges with regard to collaboration. For example, as described further below, in Group 6, there was obvious tension between two pairs of students as they worked in parallel on two different designs. However, when asked to discuss how the group worked together, students reported that "it was pretty decent" and "I think it went good".

\section{Research Question 2: How do students approach a novel engineering design task following their participation in the engineering course?}

Analysis of observation data indicate that students' approaches to the task fell into three major categories: analytical, tinkering, and design-based. Students adopting the analytical approach generally treated the task as a math problem. Within this group, students who appeared to have an accurate understanding of the problem focused on completing relevant calculations (e.g. using the Pythagorean theorem to calculate the length of a ramp with the prescribed slope).

Interestingly, these students tended to immediately determine that a ramp was the solution to the problem, and typically did not devote time to considering alternative design solutions or the particular features of the ramp design. Indeed, these groups devoted relatively little, if any, time to prototyping. Other students who adopted the analytical approach did so in spite of a clear lack of understanding of the problem. For example, the two students in Group 2 devoted the majority of the design session to measuring various materials (straws, string) to correspond to the dimensions of the train car in the diagram. Asked to describe the problem they were solving, one student stated "How many of all of this can equal to the measurements of this?" (pointing to the diagram). For these students, it seems that they saw the ruler among the task materials and the dimensions on the diagram and, without a clear understanding of the actual problem, pursued the task as an activity focused on measurement.

Students who exhibited the tinkering approach immediately began exploring the task materials, handling them in ways that varied in the degree to which they addressed the problem. Some students devoted several minutes to examining the various materials, making observations about how strong they were, what they could be used for, or how they could be combined. These 
students tended to then create solutions suggesting that, while they understood the overall goal of transporting the elephant onto the train car, they overlooked key requirements of the challenge. For example, following several minutes of experimenting with various materials, one student used straws, string, and cardstock to create a catapult that would launch the elephant, as a projectile, into the train car. Other students who took the tinkering approach focused on aspects of the task description that were tangential to the central problem. For example, two members of Group 1 devoted approximately ten minutes to making various components of a habitat for the elephant (food, a water bowl, a bed). When asked to describe what they were creating, these students referenced the detail in the task description stating that "the elephants must be well taken-care of."

Students who demonstrated the design-based approach generally began by referencing the problem, sometimes conferring with other students to confirm their understanding of the problem and requirements. These students then focused on creating design drawings and/or prototypes using the task materials. Unlike students in the "tinkering" category, students in this group typically considered multiple designs and were more likely to discuss the merits of particular design features, often referring to relevant criteria and constraints within the problem description. This design-based approach most closely resembles the model used throughout the engineering courses.

Analysis of observation data indicate variations in the degree to which student groups applied the engineering design process as they completed the novel engineering design task. Figure 3 below illustrates the degree to which students in each group engaged in the various stages of the engineering design process as they completed the task. As noted above, Group 2 did not achieve a basic understanding of the problem and was therefore unable to evaluate, prototype, test, or communicate a design solution. Observations of each of the other groups provided at least partial evidence that students engaged in multiple EDP stages as they completed the task. Table 2 presents illustrative examples of the types of student behaviors that were coded as indicative of EDP engagement.

Interestingly, although the task was conducted in the context of their engineering class and just after students had participated in a focus group in which they discussed previous work with the engineering design process, students did not explicitly reference the EDP generally or its particular stages at any point as they completed the task. One group (Group 5) referenced the engineering design process during the debrief discussion following the task, recalling the poster in their classroom illustrating the EDP and then describing how it was important for their group to devote sufficient time to understanding the problem before they began prototyping a solution. When asked whether the elephant task was similar to anything they do in their engineering class, students in some groups mentioned the use of mathematics and measurement, however, students did not draw connections related to solving problems using the engineering design process. 


\begin{tabular}{|c|c|c|c|c|c|c|c|}
\hline Group & Approach & 1. Identify & 2. Understand & 3. Ideate & 4. Evaluate & $\begin{array}{l}\text { 5. Prototype } \\
\text { and Test }\end{array}$ & 6.Communicate \\
\hline 1 & Tinkering & & & & & & \\
\hline 2 & Analytical & & & & & & \\
\hline 3 & Analytical & & & & & & \\
\hline 4 & $\begin{array}{l}\text { Design- } \\
\text { based }\end{array}$ & & & & & & \\
\hline 5 & $\begin{array}{l}\text { Design- } \\
\text { based }\end{array}$ & & & & & & \\
\hline 6 & $\begin{array}{l}\text { Design- } \\
\text { based }\end{array}$ & & & & & & \\
\hline \multirow{3}{*}{$\begin{array}{l}\text { Magnitu } \\
\text { Codes }\end{array}$} & & o Evidence & \multicolumn{5}{|c|}{ No evidence that students engaged in particular stage of EDP. } \\
\hline & & artial Evidence & \multicolumn{5}{|c|}{$\begin{array}{l}\text { Partial evidence that students engaged in particular stage of EDP. Student } \\
\text { behaviors could be considered indicative of EDP engagement; however, they } \\
\text { occur infrequently (e.g. 1-2 times or only by an individual student) or appear } \\
\text { to occur incidentally rather than as purposeful engagement in the EDP. }\end{array}$} \\
\hline & & lear Evidence & \multicolumn{5}{|c|}{$\begin{array}{l}\text { Clear evidence that students engaged in particular stage of EDP. Student } \\
\text { behaviors clearly indicative of EDP engagement. }\end{array}$} \\
\hline
\end{tabular}

Figure 3. Matrix Illustrating EDP Engagement During Elephant Task by Group 
Table 2. Illustrative Examples: EDP Engagement During the Elephant Performance Task

\begin{tabular}{|c|c|c|}
\hline EDP Stage & Code Definition & Illustrative Example \\
\hline Identify & $\begin{array}{l}\text { Student(s) review and/or discuss the problem } \\
\text { statement. Includes any statements students } \\
\text { make about the problem at the beginning of the } \\
\text { task ask well as references to the problem as } \\
\text { students engage with the task. }\end{array}$ & $\begin{array}{l}\text { When one student in Group } 6 \text { begins using materials to build a model of the box car, } \\
\text { another student re-focuses the group on the problem: } \\
\text { S2: Let's say this is the box car (using box?) } \\
\text { S1: Alright. We could do that. } \\
\text { S2: and here is the elephant (using elephant). } \\
\text { S1: You could use these as axels -You could have these like go through here if it was, you } \\
\text { know an actual box car. This would have like a hub. } \\
\text { S2: We don't care about the box car! We 're just trying to transport the elephants. } \\
\text { S1: I know, but you have to have an axel to roll it. } \\
\text { S2: We don't care about the box car. Let's just worry about the elephants... We are just } \\
\text { trying to solve the ramp. We don't care about the box car. }\end{array}$ \\
\hline Understand & $\begin{array}{l}\text { Student(s) review and/or discuss the } \\
\text { requirements and constraints within the } \\
\text { problem scenario. }\end{array}$ & $\begin{array}{l}\text { Students in Group } 4 \text { begin by reading problem statement multiple times, underlining key } \\
\text { details. One student paraphrases the slope requirement for the group: } \\
\text { "So, they can't climb more than one foot up for every two feet they have to walk straight." }\end{array}$ \\
\hline Ideate & $\begin{array}{l}\text { Student(s) brainstorm ideas for solutions to the } \\
\text { problem, independently or as a group. May } \\
\text { include sketching or manipulating materials to } \\
\text { illustrate potential solutions. }\end{array}$ & $\begin{array}{l}\text { Three students in Group } 5 \text { discuss their ideas. } 2 \text { students sketch ramp designs as they } \\
\text { discuss their ideas, focusing on the measurements of the ramp. Another student uses } \\
\text { cardstock to illustrate her ramp idea stating, "a hands-on model will be easier to show you } \\
\text { what I'm thinking we do." }\end{array}$ \\
\hline Evaluate & $\begin{array}{l}\text { Students compare various design ideas, discuss } \\
\text { the pros/cons of an individual design idea, or } \\
\text { discuss whether a potential solution is likely to } \\
\text { meet the requirements outlined in the problem } \\
\text { statement. }\end{array}$ & $\begin{array}{l}\text { Two members of Group } 6 \text { evaluate the merits two alternative ramp designs, one that flips } \\
\text { up and one that would slide under the box car: } \\
\text { S1: You could have where it folds up like this (lifts cardstock to illustrate ramp movement) } \\
\text { or you could have where it slides up under it.... } \\
\text { S2: Alright, so say this is your ramp, so it's off the ground, you could have it so there's a } \\
\text { notch up under it so it slides all the way in, or you could have it where it flops up like this } \\
\text { and closes it so they can't get out. } \\
\text { S1: Yeah, I think the sliding... because it would be easier than one person lifting it up. } \\
\text { S2: and probably safer 'cuz they could probably push it down (referring to flip-up ramp). }\end{array}$ \\
\hline $\begin{array}{l}\text { Prototype \& } \\
\text { Test }\end{array}$ & $\begin{array}{l}\text { Students use materials to build and test a } \\
\text { solution to the problem. May include detailed } \\
\text { drawings or physical models. Note: Given the } \\
\text { nature of the task and time limitations, students } \\
\text { are not expected to formally test solutions; } \\
\text { however, they may discuss how they would test } \\
\text { solutions or informally test certain properties of } \\
\text { a solution (e.g. pushing down on a ramp to test } \\
\text { strength). }\end{array}$ & $\begin{array}{l}\text { Students in Group } 1 \text { immediately begin working with the materials, with each student } \\
\text { combining various materials to build contraptions to transport the elephant. } \\
\text { S1: (uses notecards and straws to create a platform for the elephant) } \\
\text { S2: Who's carrying him? Let's make a crane that will lift this thingy up (pointing to } \\
\text { platform). } \\
\text { Students then use straws and cardstock to build a crane-like device that attaches to the } \\
\text { elephant platform. }\end{array}$ \\
\hline Communicate & $\begin{array}{l}\text { Students describe their solution, identifying key } \\
\text { features of the design and describing how they } \\
\text { believe it addresses the problem. }\end{array}$ & $\begin{array}{l}\text { During debrief discussion following the design session, Group } 5 \text { presents their design: } \\
\text { What we decided, what we designed is... you would have the ramp, the dimensions of the } \\
\text { ramp (pointing to their calculations), you'd have it made out of metal and something you } \\
\text { could fold up from the bottom, and you can kind of fold the path up to the car to put it } \\
\text { inside of the car where the elephants are... because it said that it needed to be inexpensive } \\
\text { and easy to store and transport, this is what we think is the best way to go. }\end{array}$ \\
\hline
\end{tabular}


In addition to variations in EDP engagement across groups, observation field notes documenting student collaboration indicate variations within each group. It was common for one or two students to lead and even dominate the development of designs within each group. Although gender differences were not a specific focus of this study, gender dynamics related to collaboration emerged from the observation data. Specifically, in each of the mixed-gender groups, there were clear instances of the boys in the group dominating the design session and, in some cases, explicitly dismissing their female classmates' ideas. For example, Group 6's performance task session was dominated by the two boys in the group working together to design and prototype a ramp design. Early in the session, one of the two girls in the group quietly folds a notecard to illustrate an idea she has for a staircase, which she shows to the other girl in the group. In the following exchange, one of the boys asks her about what she had made and then abruptly dismisses the idea:

\section{S1: What is that? \\ S2: (showing notecard folded as stair design) A stair for the elephants. \\ S1: You don't do stairs. It's going to have to be like a flat ramp. \\ S2: Well, I am making up an idea. \\ S1: Well, we're working as a group. You can't have your own thing.}

In spite of this dismissal, she continues working on her staircase design. Throughout the remainder of the session, when the group is asked to share what they are working on, the boy tells her to "shhhh!" as she attempts to describe her idea. During the debrief discussion, in which students were asked to describe their solutions to the problem, she is eager to share her idea, "my first idea is that we could make a stairway that is one foot step down and two feet across, like this (showing card folded as staircase). My idea was shut down." The boys then state that the stair design would not work, arguing that any materials strong enough to hold an elephant would result in a staircase that was too heavy for someone to transport. Although she quietly argues "maybe there is material that's strong and not heavy," she ultimately concludes that her design wouldn't work, echoing the boys' critique of her design: "my stair wouldn't work because it would be too heavy to transport and the elephants would break through it."

\section{Limitations}

This study contributes to previous research on student engagement in collaborative engineering design; however, it is not without limitations. Because the study relied primarily on audio data and observation field notes, we were limited in the degree to which we could capture and analyze the nuances of student interactions with each other and the task materials as they completed the design activity. For example, although we could reliably code for EDP engagement at the group level, without video footage of students completing the task, we were not always able to capture individual student actions or more nuanced group dynamics. Additionally, due to the relatively small sample, although findings may suggest potential patterns and tendencies of middle school students participating in the engineering course, we cannot necessarily draw conclusions about collaborative engineering design experiences beyond the students who participated in this study. 


\section{Discussion}

Students' descriptions of their collaborative design experiences highlight both the promises and the challenges of facilitating groupwork in the context of middle school engineering courses. Students clearly articulated their appreciation of opportunities to collaborate with their peers. Interestingly, although some students noted that they enjoyed the social aspect of working with their friends, when describing the benefits of collaboration, they focused primarily on the ways in which working together resulted in more successful designs or a more efficient design process. At the same time, observation and focus group data revealed certain challenges students may face when collaborating on a design challenge, including specific dynamics that may prevent girls and other historically marginalized students from fully engaging in the engineering design process. Notably, even groups that struggled to cooperate during the design task tended to report positively on the group collaboration when asked to reflect on how they worked together during the task. Students' reluctance to reflect on and discuss their group's challenges with collaboration suggests that students may either be unaware of such challenges or may find it difficult to address challenges they face when collaborating with peers. This preliminary finding suggests a need for phenomenological studies that look more closely at how students experience and evaluate collaborative engineering activities. These findings also suggest a clear need for carefully scaffolding collaborative engineering design, underscoring the importance of resources to support productive group work and empower students and teachers to address problematic group dynamics, particularly when the ideas and contributions of marginalized students are not recognized.

The study also adds to our understanding of the ways in which engineering design experiences, and exposure to engineering design within the STEM-ID courses, in particular, may influence students' subsequent application of the engineering design process. Even after many students had spent up to three semesters in the engineering course, most student groups did not explicitly reference or systematically apply the engineering design process as they worked through the performance task. Indeed, several groups did not seem to understand the task as an engineering design challenge at all, instead interpreting it as a mathematics problem. The only group that explicitly referenced the engineering design process in the debrief portion of the design session (Group 5) was the same group that demonstrated clear evidence of engaging in each stage of the engineering design process as they completed the task. This correspondence between articulating the engineering design process and spontaneously applying it suggests that this particular group had internalized the process in a way that others had not and that this internalization may have influenced how they approached the task.

Although application of the engineering design process was somewhat limited across groups, the fact that most groups evidenced at least partial evidence of engaging in multiple stages of the process suggests that their experience with the engineering design process in the STEM-ID course sequence may have had some influence on how they approach novel problems. While we cannot draw causal inferences between participation in STEM-ID and how students approached this particular task, given relatively sustained exposure to the course and the fact that the STEMID courses represent the major curricular effort related to engineering design in the participating schools, students' participation in the course would be the most likely experience to influence their application of the engineering design process in the design task. Developing a more 
nuanced understanding of the potential long and mid-term effects of middle school students' experiences within engineering curricula represents an important goal for future research.

Acknowledgements

This material is based upon work supported by the National Science Foundation under Grant No. 1238089. Any opinions, findings, and conclusions or recommendations expressed in this material are those of the author(s) and do not necessarily reflect the views of the National Science Foundation or Georgia Institute of Technology. For additional information about the research related to this project see https://ampitup.gatech.edu.

\section{References}

[1] C. Snyder, "Core ideas of engineering and technology: Understanding a framework for K12 science education.” Science Scope, Jan. 2012.

[2] M. Hynes, C. Mathis, S. Purzer, A. Rynearson, and E. Siverling, "Systematic review of research in P-12 engineering education from 2000-2015," International Journal of Engineering Education, vol. 33, no.1, pp. 453-462, 2017.

[3] C.M. Cunningham and G.Y.J., Kelly, "Epistemic practices of engineering for education," Science Education, vol. 101, no.3, pp. 486-505, 2017.

[4] K.B. Wendell, C.G. Wright, and P. Paugh, "Urban elementary school students' reflective decision-making during formal engineering learning experiences". Proceedings of the 2015 American Society for Engineering Education Annual Conference and Exposition, Seattle, $W A$.

[5] J. Gale, M. Alemdar, J. Lingle, S.H. Newton, R. Moore, and J. Rosen, "Developing engineering proficiency and self-efficacy through a middle school engineering course". Proceedings of the 2018 American Society for Engineering Education Annual Conference and Exposition, Salt Lake City, UT.

[6] M. Honey, G. Pearson, and H. Schweingruber, (Eds.), STEM integration in K-12 education: Status, prospects, and an agenda for research. Washington, DC: National Academies Press, 2014.

[7] K. Becker and K. Park, "Effects of integrative approaches among science, technology, engineering, and mathematics (STEM) subjects on students' learning: A preliminary metaanalysis," Journal of STEM Education: Innovations and Research, vol. 12, no. 5-6, p. 23, 2011.

[8] M. Alemdar, R.Moore, J. Lingle, J. Rosen, J. Gale, M. Usselman, "The impact of a middle school engineering course on students' academic achievement and non-cognitive skills," 
International Journal of Education in Mathematics, Science, and Technology, vol. 6, no. 3, 363-380, 2018.

[9] J.D. Bransford and D.L. Schwartz, "Rethinking transfer: A simple proposal with multiple implications," Review of Educational Research, Vol. 24, 1999.

[10] M.A. Ruiz-Primo, R.J. Shavelson, L. Hamilton, and S. Klein, "On the evaluation of systemic science education reform: Searching for instructional sensitivity," Journal of Research in Science Teaching, vol. 39, no. 5, 369-393, 2002.

[11] H.B. Carlone, J. Haun-Frank, and A. Webb, "Assessing equity beyond knowledge- and skills-based outcomes: A comparative ethnography of two fourth-grade reform-based science classrooms," Journal of Research in Science Teaching, vol. 48, no. 5, pp. 459485, 2011.

[12] C.M. Cunningham and C.P., Lachapelle, "Engaging all students in engineering". Proceedings of the 2012 American Society for Engineering Education Annual Conference and Exposition, San Antonio, TX.

[13] K. J. B. Anderson, S. S. Courter, T. McGlamery, T. M. Nathans-Kelly, and C. G. Nicometo, "Understanding engineering work and identity: A cross-case analysis of engineers within six firms," Engineering Studies, vol. 2, no. 3, pp. 153-174, 2010.

[14] M.E. Jordan and R.R. McDaniel Jr, "Managing uncertainty during collaborative problem solving in elementary school teams: The role of peer influence in robotics engineering activity," The Journal of the Learning Sciences, vol. 23, no.4, pp. 490-536, 2014.

[15] National Research Council, Next Generation Science Standards: For states, by states. Washington, DC: National Academies Press, 2013.

[16] Illustrative Mathematics. Standards for Mathematical practice: Commentary and Elaborations for K-5. Tucson: AZ, 2014. 